\title{
Building on strengths: A new framework for positive youth development program practice
}

\author{
Kathryn Seymour \\ k.seymour@griffith.edu.au
}

\begin{abstract}
This article introduces a new strengths-based approach to youth development program practice developed in Queensland, Australia. This approach is encapsulated in a good practice framework, its six principles, their underlying indicators and examples of action. The framework is a wholly new synthesis of academic, youth and practitioner expertise, and demonstrates the complex ecological nature of youth programs and the bi-directional links between the diversity of staff and youth needs, and contributions made within the program environment. I introduce the framework by discussing each of the six principles, which focus on the themes of learning and development; leadership and decision making; an inclusive ethos; community service; partnerships and networking; and ethical promotion. Taken together, the principles presented here embody an innovative, comprehensive and comprehensible framework for volunteer and paid youth practitioners, service providers and youth studies scholars.
\end{abstract}

\section{Introduction}

As the traditional family and community structures of Western societies face ever greater pressures from relentless economic and technological innovation and cultural change, the lack of an accessible, structurally rigorous conceptual framework to guide good practice in youth program design is being felt worldwide as never before. Hitherto, policy frameworks have been found wanting by focusing on youth as 'problems', highlighting perceived 'deficits' and working towards a prescriptive understanding of youth development, often loosely connected (if at all) to the latest and most relevant scholarship. The need is now becoming acute for a new framework to guide program design and implementation with reference to youth strengths rather than deficits, which is also capable of bridging the enduring divide between scholarly research and practitioner expertise. While youth development organisations increasingly are expected to gather their own quality research-based evidence of the impact of their programs for funding agencies and the wider public, there is persistent doubt among practitioners and researchers alike about what constitutes high-quality, well-designed and effective programs 
(McLaughlin and O’Brien-Strain 2008: 313; Mekinda and Hirsch 2014: 221; Wray-Lake and Syvertsen 2011).

In this article, I present a wholly new framework of principles that responds to these needs and pressures (Seymour 2012a). It was developed within the Queensland Youth Development Research Project (YDRP), an adult-led youth-inclusive, participatory action research program involving eight Queensland organisations (Seymour 2012b, 2015). These were: Impact: Youth Organisations Reducing Crime (Impact), ${ }^{1}$ the Boys' Brigade (BB); the Duke of Edinburgh's International Award (Duke of Ed); The Emergency Services Cadets Program (ESC); Girl Guides Queensland (Guides); Lions Clubs International Leo Clubs (Lions/Leos); The Police Citizens Youth Clubs (PCYC); and Surf Life Saving Queensland (SLS).

The main constituent elements of the framework are six principles that underpin a strengths-based approach to youth program design. The principles not only highlight good practices; they also focus on characteristics of a high-quality program environment. The characteristics of a program are necessarily complex and are inevitably realised through a bi-directional and mutually influential link with program practice. The six principles illustrate these complexities and links in the program environment through a focus on the broad themes of education; leadership and decision-making; inclusion; community service; relationship-building; and ethical promotion. Uniquely, the six principles in this framework have been designed to operate as a whole, linked to and supporting one another in an ecological approach to youth program viability. Figure 1 illustrates the dynamic bi-directional links between the principles and key characteristic themes that run across the framework.

The framework outlined here embodies a synthesis of academic, youth and practitioner expertise. Importantly, the contribution of the participating organisations throughout the YDRP, in interviews and individual and group discussions, are woven throughout this article to recognise their significant contribution to the content and development of this new and exciting framework.

\section{Good practice principles}

\section{Principle 1: Learning and development}

This principle focuses on fostering a culture of lifelong learning to meet the education needs of staff and participants. Youth development organisations and programs play an important role in the education of everyone, supporting them to be active participants in and contributors to society (Ledwith 2011: 85). Education across the life-course can be fostered by increasing access to formal and informal learning and development opportunities, and through recognition of learning achievements (Ausyouth 2003c: 37). ${ }^{2}$ Addressing barriers and increasing participation incentives can involve supporting everyone to identify and record their learning needs and goals, identifying the link between existing and new competencies and future opportunities, and learning from mistakes while celebrating achievements (ANTA 2002: 11; Intrator and Siegal 2014). Above all, the aim of this principle is to embed a strengths-based approach, which recognizes that learning involves persistence, resilience, experimentation and creativity - all of which come from giving yourself and others permission to try and to fail, and to release the fear of failure. Ellis (age fourteen, SLS) ${ }^{3}$ expressed this simply when she said that the most important 


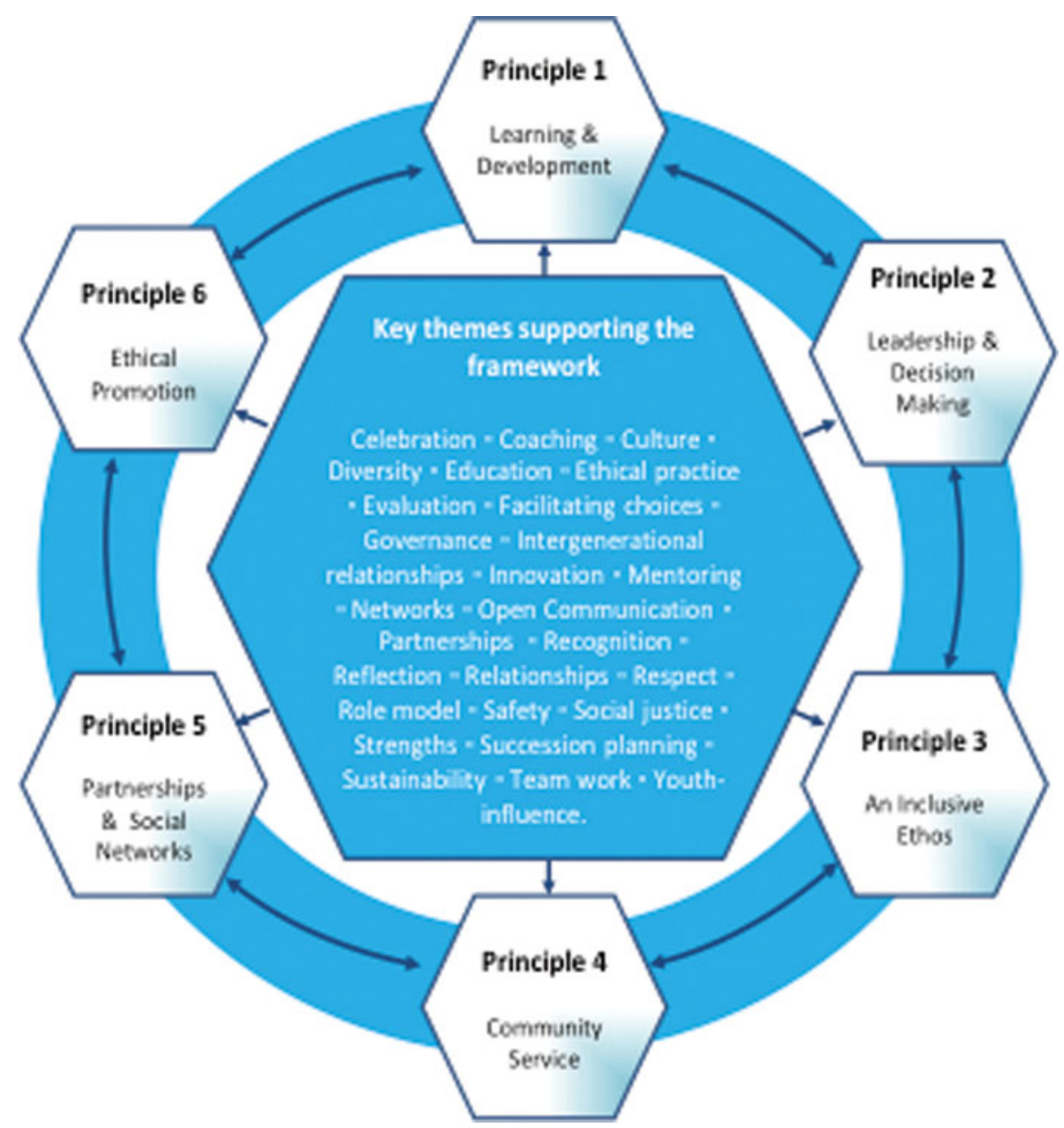

Figure 1

(Colour online) Good practice principles for strengths-based program practice.

thing she had learnt was to 'give it your hardest, and that not everything is about winning. You can learn from your mistakes and just learn from learning.'

Deschenes et al. (2010:4) note the strong connection between curriculum appeal and program effectiveness. Youth engagement is supported through activities that are fun, meaningful, relate to everyday life experiences, foster a world-view and encourage a positive vision for the future. Successfully delivering an appealing curriculum relies on the combined importance of activity design, leader training, youth voice and partnerships in creating and delivering activities (Ausyouth 2001: 29; Ausyouth 2003b: 28; Holdsworth et al. 2005: 104). Participants gave examples of the kinds of educational opportunities they felt were most important for them. Activities that had meaning for their future career, goals and identity development were high on their list. For Leela (age seventeen, ESC), learning practical skills was most important: 
Through Cadets you can gain a Certificate 2 which helps at school because you have to get a certain number of points to pass and this is one way you can get some points and it is also possible to get your Duke of Ed. Even if you don't use them directly through your career or use them directly in your life you get like invaluable knowledge. It's like common sense. It just helps you out with everything.

For David (age twenty, SLS) the most important opportunities were those where he could gain nationally and internationally recognised skills directly relevant to his future employment opportunities and for Emily (age fifteen, Guides), learning the values underpinning the Guide rules were most important. Asked why these rules were important, she replied:

Probably because I would use them in everyday life; like to respect people, to make good use of your time, like doing things for other people ... The Guide rules make you think differently about what you should be doing and what you shouldn't be doing.

An effective curriculum recognises that people are diverse, come to program activities with different skills and knowledge, as well as multiple learning styles and needs, and will also differ in age and developmental levels (Jacobs Foundation 2011: 10; PCYC and ESC, personal communication 2008). Intrator and Siegal (2014: 22-3) note that using mixed learning methodologies, such as instruction, observation, experience and critical reflection, will better support broad learning outcomes across a diverse program group. Multiple learning styles and needs can be supported by educating program leaders about the different ways in which we learn and develop. McLaughlin (2000: 14) intimates a program curriculum that teaches a number of lessons and sequentially builds a range of practical and life skills over time will support positive developmental outcomes.

A number of participants talked about stepped opportunities. Jane (age fifteen, PCYC) discussed how young people could take on leadership roles as staff at PCYC State Youth Leadership Program (SYLP) camps once they had completed all three SYLP levels: personal, leadership and community development. For Lia (15, SLS), learning how to be a surf coach involved being mentored and trained over the summer season and then practising what she had learnt:

I pretty much go with the coach now, listen to what he says with the kids and I take the younger group. Because they think that the older group won't listen to me just yet, which is fair enough. I get taught how to talk to the kids, how to show them how to ride a board properly, how to swim. Tell them where exactly they can go.

Lia says she will complete a more formal structured training course in winter so she can become a qualified surf coach. She understands the older people in her club are there to help young people learn because 'they want you to become future leaders and stay in the club'.

Meeting the educational needs of members can also bring benefits to organisation and program sustainability through more effective recruitment, development and retention of staff (Hirsch et al. 2011: 292). The BB (personal communication 2008; see also Kress 2006: 53), for example, argues that succession planning must be integrated into the training and development curriculum. Martinek and 
Hellison (2009: 11) suggest that everyone needs to experience succession planning as a positive and constructive process where strategies are fairly applied, individuals are supported and each person is able to gain the skills and knowledge they need. Rotating people across roles and responsibilities can be an effective approach to building a breadth of skill across the organisation, as well as achieving a fairer workload distribution, reducing loss of program staff through burnout $(\mathrm{H}$. Osborne, personal communication, 26 January 2015; Ausyouth 2003a: 57; Skinner 2010: 45-6). Rotation used in conjunction with other learning methods can help organisations to equip everyone with knowledge and skills across a broad portfolio (Bell et al. 2008: 1). For Sheila (age twenty-three, Leos), rotating through various committee roles was a demanding but positive learning experience:

It's good because you get to experience different aspects of the club so you learn about what it is to be a Secretary and you learn a lot of organisation from that as well as finances from the Treasurer and the President you get to sort of see over everything.

For Jade (age fifteen), a roster enabled her to share activity leadership opportunities at her Guides group, something she really enjoyed:

We've got a roster now that one week out of the month, we all like change around and swap people helping out the youngest girls ... It's good and they come and tell you how their day was and what they did at preschool or at school that day ... It's fun.

Mekinda and Hirsch (2014: 221, 223) illustrate how program leader recruitment, development and training are most effective when they are underpinned by an up-to-date understanding of the core values, ethics, skills and knowledge needed to work successfully with youth in specific social and cultural contexts (WingeierRayo 2016: 114). Adult attitudes and skills can have profound and unexpected effects (Hancock et al. 2012: 84). When adult support is viewed positively, young people have a more positive belief in themselves. At the most basic level, when staff communicate in grumpy, ill-tempered ways, everyone can end up feeling unwelcome and uncomfortable (Ausyouth 2003c: 35). As David (age eighteen, PCYC) explained, when staff 'yell', it can be very intimidating and it 'makes me just want to like go to the back of the bus, with all the other people, to hide'.

There is no doubt that skilled program leaders are important for successful work with children and young adults, each other and their community. An organisational culture of lifelong education will support the professional development of program leaders by valuing and utilising their existing skills and knowledge, and recognising and developing their potential (Hirsch et al. 2011: 290; Skinner 2010: 50). Program leader development can be supported by providing opportunities for peer-to-peer coaching and mentoring, evaluation of training curriculum, regular staff meetings and dedicated support roles (Ausyouth 2001: 47; Deschenes et al. 2010: 7).

\section{Principle 2: Leadership and decision-making}

This principle focuses on young people's needs and interests with regard to shaping their organisations and programs. Actively engaging with everyone in leadership and decision-making is a central feature of strengths-based organisations and programs (Ausyouth 2003c: 40; Martinek and Hellison 2009). Good leadership and 
decision-making utilises skills from across the four core life-skill areas identified by the Jacobs Foundation (2011): critical thinking and cognitive skills; coping skills and self-management; social and moral skills; and communication skills. A strengths-based approach will support everyone to engage with each other as they work together shaping and creating participation opportunities. Bell and colleagues (2008) argue that shaping participation in partnership with children and young adults better supports their engagement, because the methods chosen are more likely to be accessible, engaging and relevant to them.

Significant adults and an organisational culture of lifelong education support successful youth engagement in organisational and program leadership roles. When everyone is equipped with the skills they need to share leadership and to understand how their own use of power can include or exclude people, they are more likely to be able to lead effectively (Holdsworth et al. 2005: 80). Moreover, the accessibility and effectiveness of leadership educational opportunities are increased when mixed teaching methodologies are used, and flexible and diverse organisational leadership opportunities are provided (Guides, personal communication 2008; MacNeil and McClean 2006: 99-100). For Kevin (age twenty-one, PCYC), 'seeing the decisions that are made' had given him an insight into how difficult decision-making can be. He reflected that 'hard decisions' were particularly difficult when he could see they may have negative outcomes for some people. On the flipside, having the opportunity to travel, to connect with the community and to be 'out there' as a leader was incredibly rewarding.

Creating leadership opportunities is also an important feature of strengths-based succession planning, which can present challenges for young adults and youth organisations because, as Wierenga (2003: 23) explains, young people:

have less access to structural power than many other groups. Young people are one minority group that have considerable numbers below the age of legal majority ... Unlike other minority groups, children and young people keep losing their best representatives and spokespeople because they keep growing up. Because of these things, young people's involvement ... needs to keep being renegotiated.

The impact of 'growing up' on young adults exiting youth leadership roles and the resulting continuous cycle of a 'loss of organisational capital (goal momentum and institutional memory)' is a unique and real challenge (Kress 2006: 53). In addition to succession planning for targeted youth roles, youth organisations can support and engage with retiring youth leaders to support their transition into other leadership and decision-making roles. One young PCYC leader explained her experience:

So I did that (Tomorrows Inspired Leaders Today) last year and then, that only goes from the ages of sixteen to twenty-one and I ran out of that age group last year ... and I'm now twenty-two. So I'm still an advisor for the younger ones and that because I do get the odd occasional phone call from the girl who's taken over from me - 'how do I do this?' (Marnie, age twenty-two).

When the sharing of knowledge and skills has been fostered among a diversity of people, sustainability of programs is more likely to be assured as different people move into and out of roles (Ausyouth 2003b: 27). A strengths-based organisational approach engages young people in decision-making that is active, purposeful, valued and respected. This approach is consolidated and enhanced when it involves 
a wider group of young people beyond the formally recognised youth leadership group.

Programs that respond to this need are designed with multiple components and tasks that can be individual or group based, thereby offering everyone opportunities to develop their leadership and decision-making skills and to take responsibility for a full range of tasks and activities (Ausyouth 2001: 25, 33, 37; Intrator and Siegal 2014: 112). Program activities can also be designed to incorporate different roles to fit different participant levels of knowledge and skill, in order to better enable the development of leadership and decision-making expertise. Mixed youth-led, adult-led and intergenerational processes can be used to provide opportunities for participants to be involved in, or responsible for, program and activity decisions from thinking about, designing and evaluating the activities in which they take part and their group norms to the use of activity funding (Ausyouth 2001: 25, 37; Larson and Angus 2011: 288). Including flexible non-core content enables small changes to be made that can substantially improve young people's experiences (Mekinda and Hirsch 2014: 223).

\section{Principle 3: An inclusive ethos}

This principle contends that nurturing an inclusive ethos will enrich and address different needs across organisations, programs, participants and the local community. An inclusive ethos requires a commitment to social justice as a fundamental component of youth work (Martinek and Hellison 2009: 27-37). While it can be defined in different ways, Beck and Purcell (2010: 15) usefully describe social justice as:

respecting and valuing diversity and difference; challenging oppressive and discriminatory actions and attitudes; addressing power imbalances between individuals, within groups and society; committing to pursue civil and human rights for all ... [and] seeking and promoting policy and practices that are just and enhance equality whilst challenging those that are not.

Youth-inclusive organisations and programs strengthen communities and help to make them better places to live (Ausyouth 2003a). They also support children and young adults to be civically engaged, and to advance social justice and social change (Delgado 2015: 53-4, 58). This principle is underpinned by the vision of an organisational and program environment where inclusion and respect for all people is fostered, regardless of their backgrounds, opinions, experience, skills, interests, needs and capacity (Gilchrist and Rauf 2006: 22). Emily (age 15, Guides) talked about how the opportunity to discuss issues without fear of being teased was an important part of being a Guide. In her experience, everyone in her group was able to safely express their opinion on many different social, political and religious issues. The vision of an inclusive ethos necessitates the provision of ongoing support to help everyone build an environment that actively counters bias and discrimination, builds connections while acknowledging the social and economic locations of people and uses power and control in a conscious and reflective way (Beck and Purcell 2010: 73-4; Gibbs et al. 2014: 78; Ledwith 2011: 146-7). Promoting, nurturing and maintaining an inclusive ethos can be supported by governance frameworks with a clear framework of policies, procedures, strategies and actions (Gilchrist and Rauf 2006: 22). Evaluation can be used to ensure high-level policies are effectively implemented and translated into practice (Scott 1990: 146-7). Building an 
inclusive ethos is also supported by being inclusive of new ideas and different ways of thinking about and doing things. New ideas help organisations and programs to remain vibrant and relevant to different circumstances, youth, community and social needs, and to respond to shifting social, cultural, place and spatial contexts (Ausyouth 2003b: 19).

By bringing different perspectives to problem-solving, an organisation or program can change attitudes, challenge assumptions and discover new ideas and ways of doing things (Ausyouth 2001: 39; Petrie 2011: 136). Innovative thinking can be encouraged by inviting people external to the program or organisation to present new ideas, and by developing a culture of openness to new ideas, freedom and innovation (Duke of Ed, personal communication 2008). Being creative and innovating over time is also important, as Joe (age nineteen to twenty-five, BB) explains:

Being the main leader for the boys has helped me put in where I want to see them go and I think that's one thing because times have changed so we have to change their activities for them and I think that's something that I brought in. It was something where [older leaders] had these ideas and I said no, we need to change them because that's not going to apply to the boys these days.

Asked what sorts of things he had introduced, he explained:

Well, we've introduced a lot more physical activities ... A lot less of the crafts and stuff ... If we do crafts it has to be more extravagant, we can't just do a little thing for older boys, we need to do something big and get them excited. So I think their latest one was building suits of armour. And, they all seemed to have a good time.

Bringing new voices to decision-making, and challenging attitudes and assumptions as Joe did, can be risky and lead to conflict, defensiveness and uncertainty (Deeley 2015: 87, 91; Scott 1990: 149). Programs attract a range of participants who not only have differing views, but also have differing social, developmental, economic, demographic and cultural needs (McLaughlin 2000: 12, 23). A key to fostering inclusion is to support program flexibility that can accommodate these diverse needs, enabling leaders to amend program material and activities to address the specific needs of each group and young person involved (Ausyouth 2003a: 20; Ausyouth 2003c: 40; Intrator and Siegal 2014: 2).

Being open to change and listening to different points of view is important because the perspectives of young people can challenge the 'blind spots and biases' of youth practitioners and organisations (Hirsch et al. 2011: 304). Sometimes, as Ursula (age twenty-three, Guides) explained, older people can find it hard to be directed or 'told what to do' by younger people. David (age twenty, SLS) said he feels younger people sometimes want to do something differently from how it has always been done or, as Kevin (age twenty-one, PCYC) explained, try to do something again that has previously failed. Sometimes the program characteristics that participants value will differ from those valued by older people, managers, organisations or program funders, and youth priorities and needs will change over time. Building trust, a non-judgemental atmosphere and a strengths-based collective approach to working with difference and uncertainty can, however, create opportunities, support change and sustain and transform individuals, programs and organisations (Beck and Purcell 2010: 23). 
Achieving staff diversity through targeted recruitment and retention strategies can also help this transformative process. Staff diversity can encourage diverse children and young adults to participate, increase understanding and knowledge about difference, and support stronger, more effective relationships across communities (Ausyouth 2003a: 35; Ausyouth 2001: 27, 31, 37, 49). People from specific social, cultural and spiritual backgrounds are more likely to choose to participate when a program, initiative, or activity is supported by their own community (Ausyouth 2003a; Bell et al. 2008: 111). Youth programs provide unique opportunities to meet and interact with different groups of people, to visit different programs and to travel to different locations (Ausyouth 2003e: 10; Mekinda and Hirsch 2014: 224). These opportunities are valued because they help participants to develop a better understanding about society, other people and themselves (Ausyouth 2003c: 21; Pianta and Allen 2008: 26). Lucy (age sixteen, PCYC) explained how much she valued the opportunity to meet people outside her usual social network who were different to her:

The one thing that has always stood out for me in my mind is the Youth Management Team because the people who come through it and the things you learn about people and that kind of thing. You learn a lot about people and it kind of makes you step back and think I have things in life a lot easier than some other kids do.

Lucy's story shows how diversity can help to foster understanding and the valuing of difference, as well as to challenge stereotyping and discrimination (Ausyouth 2003a: 2, 32, 34-6; Bell et al. 2008: 111-12).

Underpinning an inclusive ethos is the provision of a positive social and psychological environment. Everyone plays a role in creating safe spaces where challenge, diversity and failure can be experienced positively (Ausyouth 2003a: 36; WrayLake and Syvertsen 2011: 19, 21). Jack (age eighteen, BB) noticed the difference his leaders made to his group environment by exercising their reflexive power and control to achieve a safe space for them:

When I was going through Boys Brigade, we got on with everyone ... yeah there was no one going through there that I didn't get on with at all and it was kind of a good environment, in that you weren't, there was no bullying or teasing or anything going on, it was all just there to have fun ... the environment was made by the leaders there.

Finally, an inclusive ethos is underpinned by the idea that participation is voluntary and not coerced. Having the choice to participate or not means that when young people do take part, they are more likely to do so because they want to and will be motivated to participate, take on challenges and to do their best. Liz's (age nineteen, Duke of Ed) story shows how youth strengths can be mobilised by voluntary participation:

I've always been a very introverted person and it takes a lot of effort for me to look people in the eye or strike up a casual conversation. So when I chose to involve myself with Duke of Edinburgh I pretty much had this thing that it would be like any of my other more academic pursuits that I would be able to do everything as an individual. But that's not how it works, especially when you need help during your expedition, if physically or mentally you're struggling within a 
group dynamic ... So it, by your choice, it's forcing you to engage with other people and through that develop your social skills.

Liz's story also shows how voluntary participation provides young people with opportunities to not only demonstrate effort and persistence, but to also explore their own responsibility, autonomy and identity, thus building on their personal strengths (Fredricks and Simpkins 2012: 282-3).

\section{Principle 4: Community service}

This principle links earning through service, strengthening community and building social capital. Service-learning opportunities bring many short-term and longerterm reciprocal benefits to younger and older people, their social and familial networks, and the community (ANTA 2002: 10, 24). Community service-learning can support social justice initiatives and change by promoting cooperation, exchange, understanding and the discovery of new perspectives amongst and between diverse people of all ages (Deeley 2015: 25, 74, 80). It does this by facilitating positive social interactions with others, fostering education opportunities which utilise constructive dialogue about difference, and supporting the development of internalised pro-social and civic engagement values (Wray-Lake and Syvertsen 2011: 18). For Amber, (age sixteen, Leos), the best community service activities combine working with friends, doing something meaningful for others and having fun. She explains:

Just 'cause you're all together, and like your friends and stuff and you're just cooking and having fun and helping people ... So it's good. It's not a chore you know, it's like and it feels good to kind of do something that's like beneficial kind of, like even, and it's going to sound so corny, but, beneficial to the community.

It's like I'm giving something back.

The more good practice is embedded in a service-learning activity, the more likely it is that the outcomes of the activity will be positive and achieve long-lasting benefits (Hamilton and Hamilton 2005). Good practices include the provision of safe opportunities for children and young adults to learn from, engage with, influence and contribute to their community through group and individual service-learning activities. Safe, positive learning and development experiences are facilitated when servicelearning activities are resourced, planned and structured appropriately (Wray-Lake and Syvertsen 2011: 20). A key element of strengths-based service-learning is to engage everyone in a collaborative partnership where young people participate as decision-makers, leaders and change-makers in meaningful, negotiated and understood activities (Taylor and Bressler 2000: 4, 48-9). Evidence suggests that when everyone is directly involved in planning and making decisions about service activities, they are more likely to view the activity as meaningful, benefiting everyone, and meeting diverse needs (Wingeier-Rayo 2016: 113-14).

Evaluation using processes such as structured individual, team and group reflection can ensure that partnerships are better understood, and can support the development of a deeper understanding about social issues, the challenges encountered and the resulting outcomes (Skinner 2010: 47; Wingeier-Rayo 2016: 122). Celebration involving actively and publicly recognising individual and group efforts can help to promote and value community service-learning, contributions and efforts made, and also help to sustain participation and partnerships (Ausyouth 2002c: 46). Many young people talked about how their community service 
experiences had influenced their lives. For Kylie (age sixteen, ESC), being involved in volunteering helped to build her self-esteem and self-confidence: '[It] helps me get out a lot more and be a part of the community and get recognized ... It just helps me to be able to help. I can do it, it gives me skills to learn.' For Sheila (age twenty-three, Leos), volunteering activities have developed her skills in social responsibility, caring and having empathy for others: 'You get to learn a lot about the community and the needs of the disabled and people who need help.' The biggest lesson she learnt is that 'you don't have to make a big contribution to make a difference'. For David (age 20, SLS), self-reflection on his community service had a deep and lasting impact:

In life saving, like, in the mornings and you're doing patrol and you get a lot of, like, drunks, passed out at the beach, and - or - you've done a lot of rescues with people that have been under the influence of drugs or alcohol. And you look at that and you say 'well, there's no way I'm doing that because that's what can happen', like, do a rescue - you have to do resus on 'em, like, if I do that then, you know, that could be me one day. That could be me lying on the sand passed out, unconscious.

These stories underscore the need to focus on programs that build and enhance young people's strengths. Taking part in community service activities and being exposed to difference can have a positive developmental effect, but can also be transformative in young people's lives.

\section{Principle 5: Partnerships and networks}

Successful partnerships and networks across geographically and demographically diverse organisations, programs and individuals are at the centre of strengthsbased youth organisations. Through partnerships and networks, organisations and programs can build social capital, generate knowledge and strengthen youth and community resilience (Ausyouth 2003b: 3, 7). Informal, semi-formal and formal partnerships can increase the range of resources beyond what is normally available to support the development of staff, provide activities outside a leader's expertise and enable interactions with new people (Ausyouth 2003b: 5,7; Deschenes et al. 2010: 9, 11; Lions, personal communication 2008). Connections between people, organisations, programs and businesses in a community can be established purposefully or they can be accidental, established through chance conversations. Since everyone acts as 'connectors in a network that shifts according to available time, funding, and needs', there are many opportunities for building connections (Gibbs et al. 2014: 78).

Successful partnerships require significant effort, patience, flexibility and commitment to create and sustain them (Delgado 2015: 102). During the early phase of partnerships, organisations and programs can support success by adopting a governance framework to support partnership development, allocating sufficient lead time for pre-implementation planning and working within existing community and organisation protocols (Ausyouth 2001: 35; Duke of Ed, personal communication 2008). The middle and sustaining phase of partnerships can involve documenting agreed roles, tasks and responsibilities, ensuring communication protocols support sustained, consistent dialogue, and celebrating key milestones (Ausyouth 2002b: 13; Beck and Purcell 2010: 28). Sometimes established partnerships and networks 
need to be wound up. While building enduring partnerships and networks is important, the capacity to mark the end of a partnership or network initiative in a positive way is also vital (Taylor and Bressler 2000: 67). Ending relationships in a constructive manner by disseminating knowledge about successes and lessons learnt, and supporting everyone through the closure process using a process of discussion, reflection and celebration, can open up possibilities for working together again in the future (Ausyouth 2003b: 24, 25).

Many youth taking part in the YDRP explained how partnerships and networks had expanded their activity experiences. Lukas (age eighteen) talked about his Duke of Ed experience, about how it had taught him to 'try stuff; try new things', and about how his favourite experience, camping, was an activity he would never have experienced otherwise:

I never would have done - my family's never done camping ... it was challenging and it was fun and I guess I just enjoy camping because it's completely different. It makes you appreciate what you have and what you don't have.

Through this experience, Lukas met and worked with people entirely new to him. This opportunity was important because 'the people out there were pretty inspirational'. Lukas's story suggests that important benefits flow from providing access to activities outside each leader's expertise and enabling interactions with new people. Fostering new and existing relationships between and among young and older people and extending these opportunities into the broader community is a key feature of strengths-based program practice. Structuring program activities to promote and foster new networks, connections and friendships, and ensuring leaders have the skills they need to nurture the development of safe, caring and responsive relationships, supports this goal (Ausyouth 2003a: 27; Duke of Ed, personal communication 2008; Wray-Lake and Syvertsen 2011: 13). Many participants highlighted safe, positive relationships built on trust and respect with their peers and significant adults as important for their continued engagement. Montana (age sixteen, Guides) explained that the relationships she had forged made her group 'like family'. Donald (age nineteen to twenty-five, BB), talked about the significant influence other program leaders had had on him and his life-choices:

The thing about Boys Brigade is the influence that the other people have. They are people you respect so their ability to keep you on the straight and narrow is really not matched with anything else.

Arial (age twenty-seven, Guides) explained how important having older mentors was for her ongoing involvement and sense of self-worth. Not only did she find intergenerational relationships broke down the barriers and helped her to build positive, collaborative relationships with older women; they also opened up her eyes to her abilities:

They're the ones that have had me get onto state camps, or get onto committees, take on different roles in Guiding and, you know, they have said, 'Would you consider taking on this role?', and I've gone, 'No, no, I can't do that', and they've said, 'Well why not? You know, you're capable, we'll help.'

Finally, like many other participants, Jaimie (age sixteen, SLS) explains the connection between fun, friendship, skill development and the people involved: 
[Fun is] just having a really good time - and wanting to come back, to stay involved with everyone and stay involved with everything that you're doing because you're just having such a good time and you're meeting such great people and they are all really lovely to you. It's the people who push you and build your confidence and make you feel good.

It is not surprising then that the most highlighted youth work practice for achieving positive developmental outcomes is the nurturing of strengths-based relationships, partnerships and networks with, around and for children and young adults. As these stories illustrate, youth work practice can influence the formation of important relationships with significant non-parental adults and with the other kids associated with the program (Deschenes et al. 2010: 6-7; Hirsch et al. 2011: 5; Skattebol et al. 2012: 67). In building partnerships and networks, organisations and programs can help to develop and sustain a community-wide 'web of mutual accountability and responsibility for young people' (McLaughlin 2000: 28).

\section{Principle 6: Ethical promotion}

The final principle in the framework is influenced by the argument that, as ethical youth work practice underpins quality programs, the marketing of programs necessarily involves ethical promotional strategies and practices. Ethical promotion practices help to create and raise positive organisational, program and youth profiles, build a trusted reputation, protect assets, reputation and access to members, gain funding and attract staff and program participants (Ausyouth 2002a: 5; Ausyouth 2002b: 18; Seif 2011: 67). Adopting an ethical or values-based promotional framework of guidelines, policies and strategies supported by an education program will help to maintain a consistent and ethical approach to internal and external promotional work. Ethical promotion emphasises youth strengths by using youth-safe criteria for assessing sponsorship deals and conveying positive messages about young people (Ausyouth 2002b: 18; France 2007: 162). Youth organisations are uniquely positioned to effectively affirm children and young adults as valued community members, and to profile successful youth and intergenerational partnerships (McLaughlin 2000: 12-13). Actively working with children and young adults to promote the contribution they make to their community, and researching, documenting and publicising positive stories in both mainstream and alternative media, can help to counter the dominant negative and risk-focused portrayal of youth (Delgado 2015: 11; Seif 2011: 67).

The provision of affirming role models can also help to counter negative messages about young people. For children and young adults, having the opportunity to be a role model not only provides important opportunities for responsibility recognition and the development of a balanced sense of autonomy and relatedness; it also enables them to impact positively on the lives of other youth, and supports them to develop higher levels of resilience (Martinek and Hellison 2009: xii; Mekinda and Hirsch 2014: 226). Sheila (age fourteen, SLS) illustrates the power of youth mentoring well when asked whether she has many opportunities to interact with other age groups:

Yeah, like the little redcaps we call them, or under sixes; sometimes if we've finished our training and we've got some free time and they haven't — the trainers, I suppose, they call us over and we'll help them and like we'll take them for jogs 
and we'll follow the leader and run them through the water and stuff. So we like, we get involved with them as well and even if we're out on our boards we'll just go and start paddling with them to encourage them to come along with us and I suppose it helps them get up the confidence of going out further every time and also because older kids are doing it they'll do it sort of thing.

These experiences inspired Sheila to move into leadership roles, to complete her surf rescue certificate and to take her place patrolling and helping other trainers. Soon she wants to do water safety for the competitions and when she is old enough to get her blue [child safety] card she wants to become a trainer herself. Sheila's story illustrates the significant opportunities programs offer to work with young people to collect, document and publish evidence on their achievements and positive development (Ausyouth 2003b: 33).

While program flexibility to cater for difference in youth social, developmental, economic, demographic and cultural needs supports an inclusive ethos, the importance of maintaining core program features underpins ethical promotion. Young people and their families need to know that, no matter which program group they take part in, they will find the same core program features and achieve the same core program outcomes (Holdsworth et al. 2005). Core features give the program a common purpose, and reflect values that underpin the program, and methods of program delivery, style and structure which may include specific time commitments and regularity of meetings (McLaughlin 2000: 13; Taylor and Bressler 2000: 55). The influence of a widespread recognition of core features is reflected in the stories some young people told about their joining-up experience. As Lia (age fifteen, SLS) described it:

I moved to Queensland from Sydney and we wanted something to do as a family because we didn't really do much apart from hockey in the winter. My dad used to do Surf Life Saving in Sydney so we went to Kurrawa and we signed up.

Lia's story illustrates how a strong link between program promotion, core features, and activity delivery can encourage and enable informed participation decisions (Ausyouth 2001: 37; Ausyouth 2002a: 5; Deschenes et al. 2010: 9). Maintaining core features will also contribute to a youth organisation's or program's capacity to gain the necessary funding and resources to deliver its promoted programs (ESC, personal communication 2008; also Taylor and Bressler 2000: 48). Strategies such as estimating the minimum resources needed from the start, putting strategies in place to support program sustainability and creatively extending resources through, for example, community partnerships can also help to achieve resourcing goals (Ausyouth 2003a: 57; BB, personal communication 2008; Gibbs et al. 2014). With the right people, funding and facilities, youth programs and organisations can increase their capacity to attract young people, retain them, and support them to mobilise and enhance their strengths (MacNeil and McClean 2006: 100).

\section{Conclusion}

Today, youth services in Australia and around the world stand at a crossroads. As governments respond to global financial volatility by cutting expenditure on social services, the pressure mounts on youth service providers to demonstrate the efficacy of their programs in clear and compelling terms. At the same time, youth program 
providers have to respond to unceasing demands for innovation, for relevance, and for deeper and sustained youth and community engagement in the programs and services they provide. It is to this challenging context that the Queensland Youth Development Research Project framework responds by charting a new way forward for youth service providers and their young members to engage in programs that integrate a comprehensive matrix of six guiding principles outlined in this article.

What sets the Queensland Youth Development Research Project framework apart from any other is its avowedly strengths-based orientation. Rather than designing programs based on presuppositions about the 'deficits' young people are thought to have, this new framework seeks to nourish and mobilise their strengths in leadership, learning and life-skills. By building on strengths, the framework offers to program providers new ways to constructively engage and retain young people eager to make the most of who they are, to build character, and to flourish as both individuals and team members. In addition, by using a framework specifically designed to build strengths, program providers are able to provide a distinctive and measurable narrative to funding agencies indexed to an integrated and comprehensive set of principles. Herein, the great advantage of the Queensland Youth Development Research Project framework lies precisely in its ability to facilitate mutual commitment of young people, and program providers and practitioners, in the positive work of engaging, activating and building the strengths of the rising generations.

\section{Acknowledgements}

I would like to thank Professor Ross Homel, Associate Professor Melissa Bull and Paul Wright, Griffith University, for supervising and supporting my doctoral research, which informs this article. I would also like to thank Karen Laughton, Zoe Dyason and Jonathan Haase who conducted many of the interviews drawn on for this article. Thanks also go to Lily Scourtis for her encouragement and design of Figure 1, Associate Professor Bruce Buchan for his inspiration, the Centre for Australian Studies at Copenhagen University for providing space to work and to Professor Kay Ferres, Griffith University for her unfailing mentoring.

This article represents work undertaken as part of the Queensland Youth Development Research Project, which was supported by the Queensland Youth Alliance and funded through the Australian Research Council funded Australian Postgraduate Award Industry (APAI-only) Linkage Project (LP0561854), the Queensland Government Department of Communities, and the eight Queensland programs and organisations represented in this article.

\section{Endnotes}

1 Subsequent to the completion of the good practice framework, Impact lost funding as a result of a general round of cost-cutting measures and different priorities introduced by the newly elected Queensland Government in 2012.

2 The Ausyouth national project (2000-03) was a Federal Government Department of Family and Community Services funded project aiming to advance strengths-based youth development work and increase recognition of the complementary roles of universal and targeted program work in Australia.

3 Each young person has been given a pseudonym to protect their anonymity. 


\section{References}

Australian National Training Authority (ANTA) 2002. Due credit: Examining the potential to recognise the skills achieved by young people participating in youth development programs. Melbourne: Australian National Training Authority.

Ausyouth 2001. Good practice in youth development: A framework of principles. Adelaide: Ausyouth.

_ 2002a. Better than fantastic: Young people talk about youth development. Adelaide: Ausyouth.

— 2002b. Business partnerships for youth development. Adelaide: Ausyouth.

- 2002c. Volunteering and youth development: Making a positive difference, good practice - an implementation guide. Adelaide: Ausyouth.

—2003a. Youth development for young Indigenous Australians. Adelaide: Ausyouth.

— 2003b. School and community partnerships for youth development. Adelaide: Ausyouth.

- 2003c. Learning from what young people have to say: Young people talk about their youth development experiences and expectations. Adelaide: Ausyouth.

Beck D. and Purcell R. 2010. Popular education practice for youth and community development. Exeter: Learning Matters.

Bell J. Vromen A. and Collin P. 2008. Rewriting the rules for youth participation, inclusion and diversity in government and community decision making. Report to the National Youth Affairs Research Scheme. Canberra: Commonwealth of Australia.

Deeley S. 2015. Critical perspectives on service-learning in higher education. Basingstoke: Palgrave Macmillan.

Delgado M. 2015. Urban youth and photovoice: Visual ethnography in action. Oxford: Oxford University Press.

Deschenes S., Arbreton A. Little P.M., Herrera C. Grossman J. Weiss H. and Lee D. 2010. Engaging older youth: Program and city level strategies to support sustained participation in out-of-school time. Philadelphia, PA: Harvard Family Research Project and Public/Private Ventures.

France A. 2007. Understanding youth in late modernity. Maidenhead: Open University Press.

Fredricks J. and Simpkins S. 2012. 'Promoting positive youth development through organised after-school activities', Child Development Perspectives 6(3): 280-7.

Gibbs D., McFarland D. and Irish S. 2014. 'Implementing the design of a high-tech learning space for youth', in M. Bose, P. Horrigan, C. Doble and S. Shipp (eds), Community matters: Service-learning in engaged design and planning. London: Routledge, pp. 65-80.

Gilchrist A. and Rauf T. 2006. Community development and networking. London: Community Development Foundation.

Hamilton M. and Hamilton S. 2005. 'Work and service-learning', in D. DuBois and M. Karcher (eds), Handbook of youth mentoring, Thousand Oaks, CA: Sage, pp. 348-63.

Hancock D., Dyk P.H. and Jones K. 2012. 'Adolescent involvement in extracurricular activities: Influences on leadership skills', Journal of Leadership Education 11(1): 84-101. 
Hirsch B. Deutsch N. and DuBois D. 2011. After-school centers and youth development: Case studies of success and failure. Cambridge: Cambridge University Press.

Holdsworth R., Lake M., Stacey K. and Stafford J. 2005. Doing positive things: You have to go out and do it. Outcomes for participants in youth development programs. Canberra: Department of Family and Community Services.

Intrator S. and Siegal D. 2014. The quest for mastery: Positive youth development out-of-school programs. Cambridge, MA: Harvard Education Press.

Jacobs Foundation 2011. Monitoring and evaluating life skills for youth development. Zurich: Jacobs Foundation.

Kress C. 2006. 'Youth leadership and youth development: Connections and questions', New Directions for Youth Development 109: 45-56.

Larson R. and Angus R. 2011. 'Adolescents' development of skills for agency in youth programs: Learning to think strategically', Child Development 82: 277-94.

Ledwith M. 2011. Community development: A critical approach, 2nd ed. Bristol: Policy Press.

MacNeil C. and McClean J. 2006. 'Moving from youth leadership development to youth in governance: Learning leadership by doing leadership', New Directions for Youth Development 109: 99-106.

Martinek T. and Hellison D. 2009. Youth leadership in sport and physical education. New York: Palgrave Macmillan.

McLaughlin M. 2000. Community counts: How youth organisations matter for youth development. Washington, DC: Public Education Network.

McLaughlin M.W. and O'Brien-Strain M. 2008. 'The Youth Data Archive: Integrating data to assess social settings in a societal sector framework', in M. Shinn and H. Yoshikawa (eds), Toward positive youth development: Transforming schools and community programs. New York: Oxford University Press, pp. 313-32.

Mekinda M. and Hirsch B. 2014. 'After-school programs', in D. DuBois and M. Karcher (eds), Handbook of Youth Mentoring, Thousand Oaks, CA: Sage, pp. 221-32.

Petrie P. 2011. 'Children's associative spaces and social pedagogy', in P. Foley and S. Leverett (eds), Children and young people's spaces: Developing practice, Houndmills: Palgrave Macmillan, (pp. 131-44).

Pianta R.C. and Allen J.P. 2008. 'Building capacity for positive youth development in secondary school classrooms: Changing teachers' interactions with students', in M. Shinn and H. Yoshikawa (eds), Toward positive youth development: Transforming schools and community programs. New York: Oxford University Press, pp. 21-39.

Scott D. 1990. Positive perspectives: Developing the contribution of unqualified workers in the community and youth work. London: Longman.

Seif H. 2011. 'Unapologetic and unafraid: Immigrant youth come out from the shadows', New Directions for Child and Adolescent Development 134: 59-76.

Seymour K. 2012a. Good practice principles for youth development organisations, 2nd ed. Brisbane: Key Centre for Ethics, Law, Justice and Governance, Griffith University.

_ 2012b. 'Using incentives: Encouraging and recognising participation in youth research', Youth Studies Australia 31: 51-9.

2015. 'Deficits or strengths? Re-conceptualising youth development program practice. Unpublished PhD thesis, Griffith University, Brisbane. 
Skattebol J., Saunders P., Redmond G., Bedford M. and Cass B. 2012. Making a difference: Building on young people's experiences of economic adversity. Sydney: UNSW Press.

Skinner J. 2010. 'Finding and recognising youth workers', in A. Rogers, and M. Smith (eds), Journeying together: Growing youth work and youth workers in local communities. Lyme Regis: Russel House, pp. 40-51.

Taylor S. and Bressler J. 2000. Mentoring across the generations: Partnerships for positive youth development. New York: Plenum.

Wierenga A. 2003. Sharing a new story: Young people in decision-making. Melbourne: Australian Youth Research Centre.

Wingeier-Rayo P. 2016. Service learning and community-based learning. In F. Clingerman and R. Locklin (eds), Teaching civic engagement. New York: Oxford University Press, pp. 109-24.

Wray-Lake L. and Syvertsen A. 2011. 'The developmental roots of social responsibility in childhood and adolescence', New Directions for Child and Adolescent Development 134: 11-25. 